\title{
Funding agencies urged to check for duplicate grants
}

\section{Nature probe reveals lack of oversight of researchers who win two grants for similar projects.}

\author{
BY EUGENIE SAMUEL REICH \\ AND CONOR L. MYHRVOLD
}

W hen neuroscientist Steven McIntire of the University of California, San Francisco, submitted a fiveyear, US\$1.6-million grant application to the US National Institutes of Health (NIH) in November 2001, he did not mention that just five months earlier, the US Army had awarded him \$1.2 million for a project with strikingly similar scientific aims. Both grants supported a search for genes that affect responses to ethanol in the worm Caenorhabditis elegans, which is used as a model organism to understand the effects of alcohol in humans.

McIntire, who is no longer in research but sees patients at Stanford Hospital in California, says that the two grants paid for different research: the army funds were used to look for ethanol-resistance genes, whereas the NIH's cash was spent on pinning down ethanolhypersensitivity genes. There is no implication that McIntire or any of the other researchers connected to the cases in this news story committed any wrongdoing.

But the NIH remained unaware of the army grant, and its similarity to the NIH application, throughout peer review and initial evaluation of McIntire's grant. It ultimately learned of the similarity from McIntire himself. Given that the agency wants to avoid awarding duplicate grants, the case raises questions about how effectively funders screen applications for overlap.

"The agencies are overwhelmed, and checking grants at other agencies is something that doesn't exist," says bioinformatician Harold Garner at the Virginia Polytechnic Institute and State University in Blacksburg. In a Comment

"The average grant is about $\$ 450,000$. A couple of days of labour to avoid overlap should be worth that."

article in this week's Nature (see page 599), Garner and his colleagues estimate that nearly $\$ 70$ million in overlapping funds may have been awarded over the past decade - money that could potentially have been spent on more original research.

They came to that figure after reviewing US grant applications in publicly

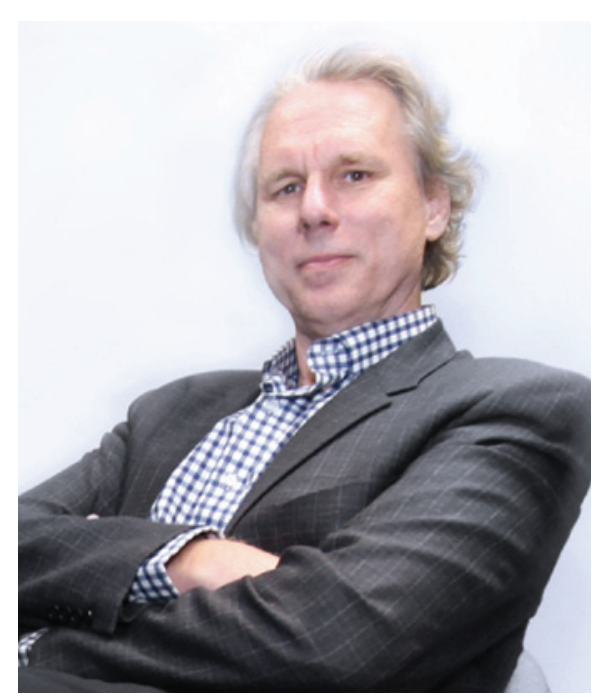

Harold Garner has used text-similarity software to identify overlap in grant applications.

accessible databases. A computerized search for duplicated text turned up 1,300 applications with potential overlap, from some 850,000 grant applications. After manually reviewing those cases, Garner's team pulled out 167 pairs that were very similar.

Because they did not have access to the full grant files, which would have allowed them to do a more thorough assessment, the team has opted not to identify those grants. But they did provide the data to Nature's news team, which subsequently obtained documentation on 22 pairs of very similar grants through the US Freedom of Information Act (FOIA). After an examination of these files, about half of the potential duplications seemed to warrant further investigation (see 'Doubling up'). This confirms that a computerized search for duplicated text "is a method to find [overlapping] grants that need to have adjustments", says Garner. The agency could then respond by reducing funding or insisting on a change in research goals.

The potential for overlap has risen since electronic preparation and submission of grant applications became the norm, says Karen Markin, who supervises grant-raising in her role as the director of research development at the University of Rhode Island in Providence. She says that it is now easier than ever for scientists to cut and paste from one document to the next.
Meanwhile, the US Congress has begun to take more interest in the issue: in an audit last year (www.gao.gov/duplication), its Government Accountability Office concluded that both the NIH and the US Department of Defense should do more to avoid duplication in their funding of health research.

Nature's review of the grant files suggests that US agencies often fail to document whether they have looked for similarities in grant proposals, or what actions they took when possible overlaps occurred. In response, the agencies say that they have a number of measures in place, including requiring researchers and their institutions to declare duplicate submissions, as well as a peer-review process that sometimes catches overlap before funding is awarded.

In McIntire's case, the potential for overlap did not come to light until well after his application had been peer reviewed, says the NIH, although before the award was made. The US Army, by contrast, learned of his subsequent NIH grant only in 2003, when reviewing McIntire's progress report, according to comments and grant files supplied by both agencies to Nature under the FOIA. In a disclosure to the NIH, McIntire wrote that although the projects had initially overlapped, they later diverged sufficiently that "there may be additional synergy between the two grants, but no scientific or financial overlap".

\section{REGULATION LABYRINTH}

Determining how much overlap is acceptable is not easy given the thicket of rules that researchers must negotiate. The NIH, for example, prohibits any scientific overlap in the projects it funds. The US National Science Foundation (NSF), by contrast, requests that researchers alert it to the submission of identical proposals to different agencies on an application cover-sheet, and that they use progress reports to inform it of changes in the grants they hold. The US Department of Defense does not always require this type of notification, but does place responsibility on researchers to ensure that no overlap exists. Not only do regulations vary between agencies, but practice on the ground is also inconsistent, says research ethicist C. K. Gunsalus of the

\section{DNATURE.COM} For responses from funding agencies on grant overlaps, see: go.nature.com/ashxgv 


\section{DOUBLING UP}

A review of agency documents for 22 grant pairs flagged up by an automated search for duplicated text suggested that about half warranted closer scrutiny.

3 GRANTS MAY NOT HAVE BEEN DECLARED TO BOTH AGENCIES

BOTH GRANTS DECLARED, BUT NOT IN A TIMELY WAY

5 BOTH GRANTS DECLARED, BUT OVERLAP NOT ADJUSTED FOR

4 OVERLAP IDENTIFIED AND RESOLVED

4 NO OVERLAP EXISTED

4 INSUFFICIENT INFORMATION TO ASSESS

University of Illinois at Urbana-Champaign. "It's a morass," she says.

That leaves plenty of room for confusion. For example, when medical researcher Allen Gao of the University of California, Davis, won an army grant to study androgen-receptor signalling in prostate cancer, officials there worked with him to change his goals so that his application would not overlap with an NIH grant that he had been awarded in 2001. But when Gao disclosed the army grant to the NIH in a 2002 progress report, the agency's officials began what they termed "extensive discussions" with Gao. They concluded that his two grants still overlapped, and reduced the NIH grant by $\$ 75,000$. "I believed that the issue had been resolved," says Gao.

Researchers say that they are eager for clarity about the limits of acceptable behaviour when chasing funding. The NIH explains that it is acceptable for researchers to submit similar requests to different agencies without disclosing other grants, because this information is required only at what is called the 'just-in-time' stage, before an award is finalized.

Some researchers already follow that principle. In one case identified by Garner's search, Michael Zuscik, a medical researcher at the University of Rochester in New York, submitted identical proposals to the army and the $\mathrm{NIH}$. But adjustments he made to the NIH proposal in response to a reviewer's scientific critique removed overlap with the army grant, he says. "This approach to securing support for research is a common method - submit the aims to more than one appropriate funding agency in the hope one will 'hit."'

Zuscik used the army money to test the effect of nicotine on fracture-healing in mice, and the NIH funds to test the effect of cigarette smoke on the same process - different science that nevertheless required some of the same control experiments. Zuscik says that the repetition was required to ensure scientific rigour. Although grant files show that Zuscik alerted the NIH to the army grant, the army has told Nature that it had not been aware of the NIH funding, and is now researching both awards to see whether they overlap.
Michael Emch, a geographer at the University of North Carolina at Chapel Hill, argues that there will always be at least some intellectual overlap between different projects run by the same researcher. Two of his grants were picked out by Garner's search because they had the same title and similar abstracts. A review of the full grant applications shows that the hypotheses and much of the text describing their methodologies is also identical. But Emch says that he did not charge both agencies for the same expenses, such as labour and lab equipment. Emch has an extremely broad research programme, and the NIH money was used to apply general medical-geography methods that had been developed with funds from the NSF to study cholera, he says.

Gunsalus points out that such grants may overlap for practical, as well as intellectual, reasons. Researchers who have large projects may carve out different lines of inquiry within them but submit similar grant applications for each one; or they might use seed funding from one agency to start a project, then try to raise additional funds from another.

Garner insists that agencies need more-consistent regulations and definitions of overlap. $\mathrm{He}$ also advocates for a central grant database that flags duplicated text automatically - although a manual review would still be required to pin down whether overlap exists. "The average grant is about $\$ 450,000$. A couple of days of labour to avoid overlap should be worth that," he says. -

\section{Magnetic logic makes for mutable chips}

\section{Alternative transistor relies on exotic semiconductor.}

\section{BY GEOFF BRUMFIEL}

$\mathrm{S}$ oftware can transform a computer from a word processor to a number cruncher to a video telephone. But the underlying hardware is unchanged. Now, a type of transistor that can be switched with magnetism instead of electricity could make circuitry malleable too, leading to more efficient and reliable gadgets, from smart phones to satellites.

Transistors, the simple switches at the heart of all modern electronics, generally use a tiny voltage to toggle between 'on' and 'off'. The voltage approach is highly reliable and easy to miniaturize, but has its disadvantages. First, keeping the voltage on requires power, which drives up the energy consumption of the microchip. Second, transistors must be hardwired into the chips and can't be reconfigured, which means computers need dedicated circuitry for all their functions.

A research group based at the Korea Institute of Science and Technology (KIST) in Seoul, South Korea, has developed a circuit that may get around these problems. The device, described in a paper published on Nature's website on 30 January, uses magnetism to control the flow of electrons across a minuscule bridge of the semiconducting material indium antimonide (S. Joo et al. Nature http://dx.doi. org/10.1038/nature11817; 2013). It is "a new and interesting twist on how to implement a logic gate", says Gian Salis, a physicist at IBM's Zurich Research Laboratory in Switzerland.

\section{MAGNETIC LOCK}

In a circuit made of the semiconductor indium antimonide, a magnetic field can lift electrons over positively charged holes, switching the device on - or deflect them into the holes, turning it off.

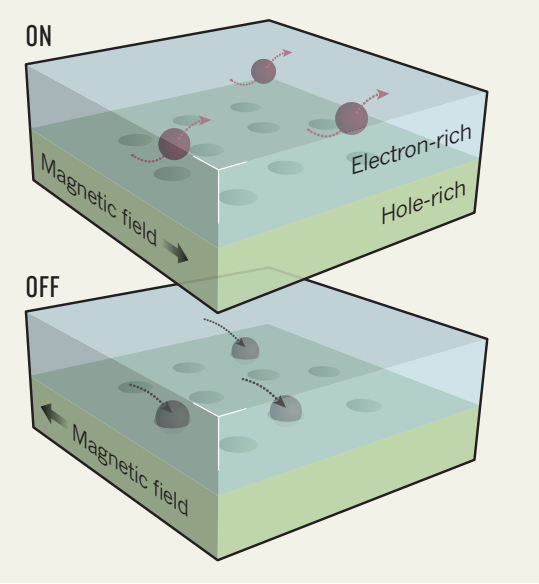

The bridge has two layers: a lower deck with an excess of positively charged holes and an upper deck filled predominantly with negatively charged electrons. Thanks to the unusual electronic properties of the indium antimonide, the researchers can control the flow of electrons across the bridge using a 